\title{
BMJ Open Statewide retrospective study of low acuity emergency presentations in New South Wales, Australia: who, what, where and why?
}

\author{
Michael M Dinh, ${ }^{1,2}$ Saartje Berendsen Russell, ${ }^{1,3}$ Kendall J Bein, ${ }^{1}$ \\ Dane R Chalkley, ${ }^{1}$ David Muscatello, ${ }^{4}$ Richard Paoloni, ${ }^{2}$ Rebecca Ivers ${ }^{5,6}$
}

To cite: Dinh MM, Berendsen Russell S, Bein KJ, et al. Statewide retrospective study of low acuity emergency presentations in New South Wales, Australia: who, what, where and why?. BMJ Open 2016;6:e010964. doi:10.1136/bmjopen-2015010964

- Prepublication history for this paper is available online. To view these files please visit the journal online (http://dx.doi.org/10.1136/ bmjopen-2015-010964).

Received 23 December 2015 Revised 29 February 2016 Accepted 21 April 2016

CrossMark

For numbered affiliations see end of article.

Correspondence to Dr Michael M Dinh; Michael. dinh@sswahs.nsw.gov.au

\section{ABSTRACT}

Objective: The present study aims to use a statewide population-based registry to assess the prevalence of low acuity emergency department (ED) presentations, describe the trend in presentation rates and to determine whether they were associated with various presentation characteristics such as the type of hospital as well as clinical and demographic variables.

Design and setting: This was a retrospective analysis of a population-based registry of ED presentations in New South Wales (NSW). Generalised estimating equations with log links were used to determine factors associated with low acuity presentations to account for repeat presentations and the possibility of clustering of outcomes.

Participants: Patients were included in this analysis if they presented to an ED between January 2010 and December 2014. The outcomes of interest were low acuity presentation, defined as those who selfpresented (were not transported by ambulance), were assigned a triage category of 4 or 5 (semiurgent or non-urgent) and discharged back to usual residence from ED.

Results: There were 10.7 million ED presentations analysed. Of these, $45 \%$ were classified as a low acuity presentation. There was no discernible increase in the rate of low acuity presentations across NSW between 2010 and 2014. The strongest predictors of low acuity ED presentation were age $<40$ years of age (OR 1.77); injury or musculoskeletal administrative and nonurgent procedures (OR 2.96); ear, nose and throat, eye or oral (OR 5.53); skin or allergy-type presenting problems (OR 2.84).

Conclusions: Low acuity ED presentations comprise almost half of all ED presentations. Alternative emergency models of care may help meet the needs of these patients.

\section{INTRODUCTION}

Emergency departments (EDs) were designed to triage and manage acutely unwell and injured patients. ${ }^{12}$ Over the past

\section{Strengths and limitations of this study}

- Large statewide data set of all emergency department presentations with low acuity presenting problems.

- Use of standard definition for low acuity consistent with current Australian Institute of Health and Welfare.

- Study period is 5 years.

- Will inform and support development of alternative models of urgent healthcare.

- Used presenting problem rather than final diagnosis.

few decades, demand for use of EDs has increased disproportionately to population changes. ${ }^{3-5}$ As a result, they have evolved to serve many functions, including the management of ambulatory care patients, a safety net for the socially disadvantaged, a gateway to subspecialist clinics, as well as an entry point for hospital admission. ${ }^{2}$ A substantial proportion of patients presenting to ED are now classified as low acuity presentationsthose that are semiurgent or non-urgent according to the validated tools such as the Australasian Triage Scale (ATS). ${ }^{6}$ Estimates of the proportion of non-urgent or semiurgent presentations in ED range from $40 \%$ to over $60 \% .^{3-5}$ This has raised concerns regarding service provision in EDs and the sustainability of current models of emergency care.

Many of these low acuity presentations have been characterised in the literature as 'inappropriate' or 'general practice' presentations. ${ }^{8} 9$ The definition and identification of 'inappropriate' presentations vary in the literature and have been a source of ongoing controversy as have their significance to overall ED operations. ${ }^{10}$ The reasons found to be associated with these presentations 
include access to general practitioners (GPs), convenience and self-reported perceptions of urgency. ${ }^{8} 9$ Although it has been consistently reported that these low acuity presentations as a whole do not contribute to excess length of stay or overcrowding in EDs, ${ }^{10}$ they do, however, impact on resourcing and the efficiency of the models of care currently used and their relevance continues to be debated in the media. ${ }^{11}$

Nevertheless, given that the majority of patients presenting to ED are classified as low acuity, it would seem vitally important to examine the demographic and clinical characteristics of these types of presentations. To the best of the authors' knowledge, this has not been done on a population level in Australia. By using such a large data set with ATS categories, presenting problem and hospital-level data, these results should be transferable to EDs outside New South Wales (NSW). Doing so would assist in developing models of care that promote a more efficient use of EDs, urgent care centres and general practice facilities within an integrated health system. Examples of these may include minor injury clinics, telemedicine and hospital in the home.

The objective of this study was to use a statewide population-based registry to assess the prevalence of low acuity ED presentations, describe the trend in presentation rates and to determine whether they were associated with various presentation characteristics such as the type of hospital as well as clinical and demographic variables. This information can inform health policy debate and provide evidence for the current controversy regarding appropriate ED utilisation.

\section{METHODS}

\section{Setting and design}

This was a retrospective analysis of a population-based registry of ED presentations in NSW. It was undertaken as part of the Demand for Emergency Services Trend in Years 2010-2014 (DESTINY) study. NSW is the most populous state in Australia with a population of around 7.5 million people and a land area of $850000 \mathrm{~km}^{2}{ }^{2}{ }^{12}$

\section{Data sources}

The Emergency Department Data Collection (EDDC) Registry routinely collects patient-level data on presentations to all designated EDs in NSW. Data collection includes referral source (self-referred, general practice, specialist, nursing home), mode of arrival (self-referral, ambulance), hospital facility, triage category (Australasian triage category), ${ }^{6}{ }^{7}$ presenting problem, mode of separation (admitted to hospital, discharged or died). Presenting problems allocated by triage nurses at the point of patient arrival to ED were categorised into broad clinical groups by the investigating team (see table 1).

Full data definitions for the EDDC are located at http:/ / www0.health.nsw.gov.au/policies/pd/2009/PD2009_071. html.

Hospital facilities were classified according to the current Ministry of Health definitions for designation of EDs based on case-mix, staffing and specialist facilities within each hospital. ${ }^{13}$ In brief, these range from level 6 centres comprising tertiary-level teaching hospital which are major trauma centres (including two specialist paediatric centres), level 5 centres which are tertiary-level

Table 1 Classification of triage presenting problems and emergency department diagnoses with the most common examples contained in the data set

\begin{tabular}{ll}
\hline Presenting problem category & Presenting problem examples \\
\hline Abdominal/gastrointestinal & Abdominal pain, vomiting, diarrhoea, nausea, epigastric pain, melaena \\
Cardiovascular/respiratory & $\begin{array}{l}\text { Chest pain, collapse, syncope, palpitations, shortness of breath, cough, wheeze, } \\
\text { pneumonia }\end{array}$ \\
$\begin{array}{l}\text { Chest infection, fever, wound infection, cold symptoms, abscess } \\
\text { Injury/musculoskeletal }\end{array}$ & $\begin{array}{l}\text { Road trauma, fracture, laceration, dislocation, amputation, burn, sprain, back pain, } \\
\text { limb pain, burns, falls }\end{array}$ \\
Other medical symptoms & $\begin{array}{l}\text { Abnormal results, weight loss, decreased input, lethargy, general pain, } \\
\text { hyperglycaemia, febrile neutropaenia, anaemia }\end{array}$ \\
Neurology & Headache, seizures, postictal, altered level of consciousness, stroke, cerebral \\
Mental health & haemorrhage \\
Ear, nose and throat, eye, oral & intoxication \\
Administrative procedures and & Hyphaema, foreign body eye, epistaxis, toothache, tonsillitis \\
non-urgent reviews & Prescriptions, certificates, reviews, referrals, bloods, INR check, wound dressings \\
Urinary, renal & Urinary retention, dysuria, renal colic, hydrocele \\
Social & Social problems, acopia, homeless \\
Endocrine & Diabetes, hypoglycaemia \\
Obstetrics/gynaecology & Per vaginal bleeding, miscarriage, ectopic, batholins cyst, ovarian torsion, birth \\
Allergy/skin & Anaphylaxis, urticaria, rash, cellulitis, psoriasis, eczema \\
\hline INR, international normalised ratio. &
\end{tabular}


non-trauma centres, level 4 centres which are mainly metropolitan district-level hospitals, level 3 centres which are smaller district and general hospitals, and levels 2 and 1 centres which comprise smaller rural multipurpose and urgent care centres. Estimated residential population by age and sex were obtained from the Australian Bureau of Statistics. ${ }^{12}$ Socio-Economic Index for Areas (SEIFA) and Index of Relative Socio-Economic Advantage and Disadvantage for each hospital location were also obtained from the Australian Bureau of Statistics and used as a surrogate marker of socioeconomic status within a particular hospital catchment area. ${ }^{12}$ An increasing SEIFA indicates improved socioeconomic level for a given area.

\section{Patients}

Patients were included in this analysis if they presented to an ED between January 2010 and December 2014. Patients who were dead on arrival, transferred from other hospitals or were planned presentations to ED were excluded. Facilities that did not submit any data for one or more years during the study period were also excluded.

\section{Outcome}

The outcomes of interest were low acuity presentation, defined as those who self-presented (were not transported by ambulance), were assigned a triage category of four or five (semiurgent or non-urgent) and discharged back to their usual residence from ED. This was based on the current Australian Institute for Health and Welfare (AIHW) definition for potentially avoidable 'general practice' type presentations. ${ }^{14}$ We sought to describe presentation rates, presenting problem types, predictors of low acuity presentation and length of stay.

\section{Statistical analyses}

Univariate statistics were used to compare those with low acuity presentation and those who were not.23 The $\chi^{2}$ tests were used to compare categorical variables. Generalised estimating equations (GEEs) with log links were used to determine factors associated with low acuity presentations to account for repeat presentations and the possibility of clustering of outcomes among different levels of hospital. To simplify analyses and account for potential shifts in triage practice over the years, only those presentations during 2014 were modelled excluding those with missing presenting problem data. ORs and CIs were corrected for multiple comparisons using Bonferroni correction. Given the very large sample sizes, effect sizes denoted by ORs were a priori defined as a strong effect (lower 95\% confidence limit of OR $>1.50$ or $<0.67$ ) or a weak one (upper $95 \%$ confidence limit of OR $<1.50$ or $>0.67)$. Analyses were conducted on SAS Enterprise Guide V.4.23.

\section{RESULTS}

\section{Patient population}

There were 11.8 million ED presentations during the study period. When planned ED presentations, those who were dead on arrival, transferred from another hospital or presented to a facility with incomplete data during the study period were excluded, there were 10.8 million presentations analysed. Of these, the mean age was 39.0 years (SD 26.6) and $51.3 \%$ were male. In total, 1511820 cases (14.0\%) had missing presenting problem entries. A total of $45 \% \mathrm{ED}$ presentations were classified as a low acuity presentation. Table 2 summarises the baseline demographic and clinical characteristics of low acuity and non-low acuity presentations.

\section{Trends}

The highest rate of low acuity presentations per 1000 population was in the paediatric patient population, with a decline in rates with increasing age observed (figure 1). Overall, there was no discernible increase in the rate of low acuity presentations across NSW between 2010 and 2014 . There was a $1.50 \%$ increase per annum in low acuity ED presentations in those over 80 years of age and a $1.02 \%$ per annum increase in those aged $0-9$ years.

\section{Clinical characteristics}

Low acuity presentations were associated with those under the age of 40 years, injury/musculoskeletal; ear, nose and throat (ENT)/oral/eye; skin/allergy or administrative-type presenting problem categories. A higher proportion of low acuity presentations presented during business hours (08:00-17:59 h) and on weekends. Increasing SEIFA categories were associated with a higher proportion of low acuity presentations, except for the highest SEIFA categories. Limb injuries and lacerations were the most common low acuity presenting problems across most age groups except in those aged 0-9 years where fever, rash and cough were the most common.

\section{Predictors of low acuity presentation}

After multivariable GEE modelling (see table 3), the strongest predictors of low acuity ED presentation were age $10-19$ years (OR $1.77,95 \%$ CI 1.74 to 1.80 ) compared with 40-59 years; injury or musculoskeletal administrative and non-urgent procedures (OR 2.96, 95\% CI 2.91 to 3.00 ); ENT, eye or oral (OR 5.53, 95\% CI 5.38 to 5.68 ); skin or allergy-type presenting problems (OR $2.84,95 \%$ CI 2.75 to 2.92 ) compared with abdominal/ gastrointestinal.

SEIFA categories, designation of ED, hours of presentation and sex had weak associations with low acuity presentations after adjusting for all other variables.

Within different health districts, multiple hospitals with different ED designation level occur within close proximity to each other. Presentations to level 5 or 6 EDs were strongly associated with reduced odds of low 
Table 2 Comparison of low acuity ED presentation versus other ED presentations in New South Wales 2010-2014

\begin{tabular}{|c|c|c|}
\hline & $\begin{array}{l}\text { Low acuity } \\
\mathrm{N}=4861930\end{array}$ & $\begin{array}{l}\text { Other } \\
N=5936867\end{array}$ \\
\hline Male (\%) & $2567815(52.8)$ & $2970479(50.0)$ \\
\hline \multicolumn{3}{|l|}{ Age (years) } \\
\hline $0-9$ & $1059281(21.8)$ & $804060(13.5)$ \\
\hline $10-19$ & $752898(15.5)$ & $510622(8.6)$ \\
\hline 20-39 & $1480492(30.4)$ & $1303873(22.0)$ \\
\hline $40-59$ & 921649 (19.0) & $1225014(20.6)$ \\
\hline $60-79$ & $519312(10.7)$ & $1251690(21.1)$ \\
\hline $80+$ & $128223(2.6)$ & $836821(14.1)$ \\
\hline \multicolumn{3}{|l|}{ Presenting problem } \\
\hline Abdominal/gastrointestinal & $443371(9.1)$ & 844791 (14.2) \\
\hline Cardiovascular/respiratory & $242013(5.0)$ & $1274850(21.4)$ \\
\hline Injury/musculoskeletal & $1555071(32.0)$ & $1070655(18.0)$ \\
\hline Fever/infection & $215518(4.4)$ & $228080(3.8)$ \\
\hline Neurological & $103409(2.1)$ & $376087(6.3)$ \\
\hline Other medical symptoms & $419002(8.6)$ & $520181(8.8)$ \\
\hline Mental health/toxicology & $58686(1.2)$ & $284351(4.8)$ \\
\hline Administrative, non-urgent procedures, blood tests and prescriptions & $255879(5.3)$ & $55301(0.9)$ \\
\hline Genitourinary & $93813(1.9)$ & $136733(2.3)$ \\
\hline Obstetrics and gynaecology & $56623(1.2)$ & $62095(1.1)$ \\
\hline Skin and allergy & $245322(5.1)$ & $138023(2.3)$ \\
\hline Ear, nose and throat/oral/eye & $446122(9.2)$ & $136784(2.3)$ \\
\hline Social & $11663(0.2)$ & $10604(0.2)$ \\
\hline Missing & $715488(14.7)$ & 796332 (13.4) \\
\hline \multicolumn{3}{|l|}{ ED designation } \\
\hline Levels 1 and 2 & $390954(8.0)$ & 205424 (3.5) \\
\hline Levels 3 and 4 & 2250625 (46.3) & $2242456(37.8)$ \\
\hline Levels 5 and 6 & 2220351 (45.7) & $3488987(58.8)$ \\
\hline \multicolumn{3}{|l|}{ Hours of presentation } \\
\hline 08:00-18:00 & $2634383(54.2)$ & $2980750(50.2)$ \\
\hline 18:00-23:59 & 1666326 (34.3) & $2010453(33.9)$ \\
\hline 00:00-07:59 & $561221(11.5)$ & 945664 (15.9) \\
\hline \multicolumn{3}{|l|}{ Day of presentation } \\
\hline Weekend & $1588124(32.7)$ & $1700094(28.6)$ \\
\hline \multicolumn{3}{|l|}{ Location of hospital } \\
\hline Metropolitan area & $2486761(51.2)$ & $3910795(65.9)$ \\
\hline \multicolumn{3}{|l|}{ SEIFA category } \\
\hline $850-900$ & $170646(3.5)$ & $178776(3.0)$ \\
\hline $901-950$ & 654091 (13.4) & 730629 (12.3) \\
\hline $951-1000$ & 2633973 (54.2) & $3052293(51.4)$ \\
\hline $1001-1100$ & 1230201 (25.3) & $1617190(27.2)$ \\
\hline$>1100$ & 173019 (3.6) & $357979(6.0)$ \\
\hline
\end{tabular}

acuity presentations compared with level 1 or 2 EDs (OR $0.44)$. Similarly, age $>80$ years compared to reference age 20-39 years (OR 0.18), was strongly associated with reduced odds of low acuity presentations as were cardiovascular/respiratory (OR 0.42), mental health/toxicology (OR 0.38) or neurological (OR 0.64) presentations compared to abdominal/gastrointestinal presentations.

\section{DISCUSSION}

This study was undertaken to describe the characteristics of low acuity presentations across NSW. The results demonstrated that low acuity presentations account for almost half (45\%) of all ED presentations, which is consistent with previous studies using the same definition of low acuity presentation. ${ }^{5}$ There was no appreciable trend observed in low acuity presentations, with only a slight increase in those aged $0-9$ years and those $>80$ years.

Although there is no significant increase in the rate of low acuity presentations in any particular age group in the study period, there remain significant implications in regard to the impact on ED workload, resource management, healthcare service and delivery as well as some contribution to ED overcrowding and efficiency of ED processing. 


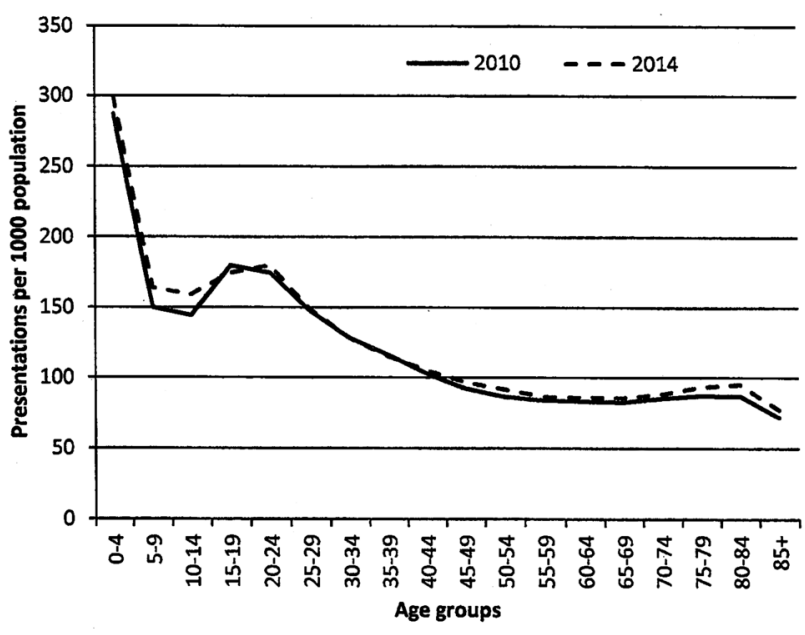

Figure 1 Rate of low acuity emergency department presentation per 1000 population.

Low acuity presentations were most commonly associated with injury (presumably minor) and musculoskeletal-related presenting problems across all ages. They were strongly associated with other presenting problem types, namely ENT/eye and oral; administrative and non-urgent procedures (prescriptions, certificates, blood tests, catheter changes); and skin or allergic-related presentations. A relationship was observed with age, with younger patients more likely to have a low acuity presentation, suggesting that alternative paediatric urgent care may be warranted. Studies in the UK demonstrated that parents preferred ED care over alternatives even when the presenting problem was non-urgent, as they understood what services were available in ED (such as radiology) and they trusted the staff that were trained in child health. ${ }^{15}{ }^{16}$ Many parents had considered or seen a GP prior to an ED presentation but either could not get an appointment or could not be managed in that setting, resulting in an ED attendance regardless. ${ }^{16}$ Furthermore, Mathison $e t$ al ${ }^{17}$ demonstrated a strong correlation between low spatial density of primary care and non-urgent ED utilisation, which is an important factor for NSW given its large size.

Time of day, day of the week and socioeconomic indices were only weakly associated with low acuity presentations in our study. Our findings are much higher than those reported by Nagree et $a l ;^{18}$ however, that study only analysed data from tertiary-level hospitals.

Whether these patients constitute 'GP presentations' is likely to remain controversial. The drivers of these presentations are multifactorial and thought to be a combination of perceived individual clinical need and health system-related factors such as cost and access to alternatives such as GPs. ${ }^{19}{ }^{20}$ Compounding the problem is the lack of an agreed definition for GP presentations to ED. ${ }^{18}$ While the AIHW definition used in this study may overestimate the prevalence of low acuity presentations, and under-represent the proportion of low acuity problems that are complex, identical criteria have also been used in a Canadian study to define low complexity. ${ }^{10}$ Alternative definitions of low acuity have been proposed incorporating consultation times of less than an hour and specific presenting problem types in consultation with the Australasian College of Emergency Medicine. ${ }^{18}$ Measuring accurate consultation times, however, remains problematic with factors such as ED role delineation, models of care, clinical designation and data collection abilities likely to affect consultation times. There is also an implicit assumption in the literature that EDs are ideal places for complex low acuity presentations, and that GPs can only manage certain diagnoses, neither of which has been substantiated. ${ }^{18}$

Another point of contention appears to be the significance of these types of presentations, given that growth in ED presentations over the past decade appears to be related to higher acuity presentations. Aboagye-Sarfo et $a l^{3}$, for instance, demonstrated a $4.6 \%$ per annum increase in ED presentations in Western Australia, which was attributed to a rise in rate of presentations with more urgent needs. Other studies, however, demonstrate that this increase in higher acuity is almost entirely attributable to an increase in presentations in the elderly, ${ }^{5}$ who present to ED with more urgent problems (such as cardiovascular and respiratory symptoms) and who are less likely to be discharged from ED, and this appears to be consistent with the findings of this study. Nevertheless, given that almost half of ED patients are low acuity, EDs need either internal or external models of care to manage this volume without impacting the overall function of the ED.

The study has a number of important implications, including the identification of patients and presenting problem types that may be amenable to alternative models of care rather than conventional ED care. First, from a health provider perspective, alternative models of care have been studied within EDs, including minor injury or 'fast-track' units staffed by nurse practitioners and GPs managing non-urgent problems either in collocated clinics or within EDs themselves. ${ }^{21-23}$ In the UK, external urgent care centres have been introduced to try to alleviate the pressure on EDs with varying utilisation. ${ }^{24}$ A Cochrane review of three observational studies comparing GPs and emergency physicians managing non-urgent presentations reported that GPs ordered fewer blood tests and X-rays but that the overall quality of evidence was weak. ${ }^{22}$ Similarly, there is paucity of evidence relating to nurse practitioners with respect to costeffectiveness and quality of care, although several studies have shown improved patient satisfaction in minor injury unit settings. ${ }^{23}$ It may be that factors associated with non-urgent presentations are outside the control of hospitals themselves. A study investigating variations in potentially avoidable ED presentations found that socioeconomic factors, particularly employment status, accounted for over $70 \%$ of the variation, with a further $15 \%$ explained by hospital factors and access to GPs. ${ }^{25}$ In contrast, this study only demonstrated a weak 
Table 3 Predictors of low acuity ED presentation using multivariable generalised estimating equations

\begin{tabular}{|c|c|c|}
\hline & Adjusted OR & $95 \% \mathrm{Cl}$ \\
\hline \multicolumn{3}{|l|}{ Age category } \\
\hline 0-9 & 1.77 & 1.74 to 1.78 \\
\hline $10-19$ & 1.77 & 1.74 to 1.80 \\
\hline 20-39 & 1.52 & 1.50 to 1.54 \\
\hline $40-59$ & (ref) & \\
\hline $60-79$ & 0.56 & 0.55 to 0.57 \\
\hline $80+$ & 0.19 & 0.18 to 0.19 \\
\hline Male & 0.96 & 0.95 to 0.97 \\
\hline \multicolumn{3}{|l|}{ Presenting problem } \\
\hline Abdominal gastrointestinal & (ref) & \\
\hline Cardiovascular/respiratory & 0.42 & 0.41 to 0.43 \\
\hline Injury/musculoskeletal & 2.96 & 2.91 to 3.00 \\
\hline Neurological & 0.64 & 0.62 to 0.66 \\
\hline Other medical & 1.88 & 1.84 to 1.92 \\
\hline Mental health/toxicology & 0.38 & 0.37 to 0.40 \\
\hline ENT/oral/eye & 5.53 & 5.38 to 5.68 \\
\hline Administrative/non-urgent procedures & 9.28 & 8.93 to 9.65 \\
\hline Genitourinary & 1.55 & 1.50 to 1.60 \\
\hline Social & 2.02 & 1.86 to 2.20 \\
\hline Obstetrics and gynaecology & 1.35 & 1.29 to 1.41 \\
\hline Skin/allergy & 2.84 & 2.75 to 2.92 \\
\hline Infection/fever & 1.34 & 1.30 to 1.38 \\
\hline \multicolumn{3}{|l|}{ Hours of presentation } \\
\hline 08:00-17:59 & (ref) & \\
\hline 18:00-23:59 & 0.88 & 0.87 to 0.89 \\
\hline 00:00-07:59 & 0.76 & 0.75 to 0.77 \\
\hline \multicolumn{3}{|l|}{ Day of presentation } \\
\hline Weekend & 1.10 & 1.09 to 1.11 \\
\hline \multicolumn{3}{|l|}{ ED designation } \\
\hline Level 1 or 2 & (ref) & \\
\hline Level 3 or 4 & 0.68 & 0.66 to 0.69 \\
\hline Level 5 or 6 & 0.44 & 0.43 to 0.45 \\
\hline \multicolumn{3}{|l|}{ SEIFA category } \\
\hline 850-900 & (ref) & \\
\hline $901-950$ & 1.04 & 1.00 to 1.07 \\
\hline $951-1000$ & 1.11 & 1.08 to 1.14 \\
\hline $1001-1100$ & 1.32 & 1.28 to 1.36 \\
\hline$>1100$ & 1.17 & 1.13 to 1.21 \\
\hline
\end{tabular}

association with surrogate markers of socioeconomic status, as well as time and day of presentation, suggesting that access to GPs may play only a minor role in these low acuity ED presentations. Given the time-sensitive nature of GP availability, promoting alternative programmes in Australia like the national bulk-billed afterhours doctor home visit needs further evaluation as to its impact on ED use. ${ }^{26}$

Second, from a health system perspective, given the substantial proportion of low acuity presentations to ED, health policy initiatives to mitigate low acuity ED demand may need to be reconsidered. Various strategies, including co-payments, telephone triage and co-located GP clinics, have been employed to curb low acuity presentations to ED. On the one hand, telephone triage and co-located general practice clinics have had negligible impacts on overall ED attendance rates. ${ }^{8} 22$ On the other hand, Selby et $a l^{27}$ reported on the effects of a US\$25-\$35 co-payment in California in 1992 and found a $15 \%$ decrease in non-urgent presentations associated with the co-payment. There was no apparent increase in mortality or unplanned hospital admissions reported in that study. Similarly, a comprehensive programme consisting of public health education, financial disincentives including a co-payment, improved access to GPs and redirection of non-urgent cases to other urgent care clinics resulted in a decline in non-urgent presentations from $57 \%$ to $18 \%$ over 12 years in Singapore. ${ }^{28}$ In addition, the overall rate of growth in ED presentations fell from $5.5 \%$ to $2.1 \%$ after the intervention. ${ }^{29}$ However, these results have not been replicated in other settings. It would also be difficult to implement these 
health policy changes without political and scientific consensus, particularly when issues around access to EDs remain highly sensitive. Studies of patient preferences of health provider (emergency or GP) seem to indicate that the decision is largely based on the perceived urgency of the presenting problem. ${ }^{30} 31$ At the very least, the results underscore the importance of coordinated policy responses to the problem of ED demand, and that these solutions are likely to take time.

There is scope to further explore the impact of socioeconomic status on presentation patterns at the individual level rather than the hospital SEIFA which our study did. Higher SEIFA hospitals may have more capacity to manage low acuity presentations and higher SEIFA individuals may not object to small co-payments for low acuity visits, and this could be explored.

\section{LIMITATIONS}

The study evaluated 5 years of data, so it is difficult to be conclusive about trends observed in this study. A number of important factors were not available, which may have improved analysis, including postcode of residence, country of origin and primary language spoken at home. Other factors such as the number of GPs per 1000 population in a given area may have allowed better estimates of the role that access to GPs plays in determining rates of low acuity presentations. Given that only one presenting problem could be coded per presentation, a further limitation exists as, in clinical practice, patients may present with more than one symptom, which could improve the predictive value of our model. It is unclear whether using final diagnoses would have changed the overall findings of the study. Given that the driver of the study was to identify patients with low acuity presentations before assessment in ED, it was deemed more relevant in this context to analyse initial presenting problems indicated by triage nurse assessments. While we used the current national AIHW definition for low acuity presentations, we acknowledge that this definition remains controversial and that some low acuity presentations may not meet the definition as the ATS mandates higher triage categories for severe pain or distress and other low acuity problems might require an admission again excluding patients from the definition.

\section{CONCLUSION}

In conclusion, $45 \%$ of ED presentations in NSW were patients self-presenting with a semiurgent or non-urgent presentation and discharged home from ED. There was no trend observed in these low acuity presentations over 5 years. These presentations were strongly associated with younger age, and certain presenting problem types such as minor injury, musculoskeletal, ENT and nonurgent procedures. Further research is needed into whether these may be amenable to alternative emergency models of care or other health policy initiatives designed to reduce overall demand for EDs and address whether these efforts would be beneficial or used successfully.

\section{Author affiliations}

${ }^{1}$ Royal Prince Alfred Hospital, New South Wales, Australia

${ }^{2}$ The University of Sydney, Discipline of Emergency Medicine, New South

Wales, Australia

${ }^{3}$ The University of Sydney, School of Nursing, New South Wales, Australia

${ }^{4}$ University of New South Wales, School of Public Health and Community

Medicine, New South Wales, Australia

${ }^{5}$ Injury Division, The George Institute for Global Health, The University of

Sydney, New South Wales, Australia

${ }^{6}$ Flinders University, School of Nursing and Midwifery, South Australia, Australia

\section{Twitter Follow Rebecca Ivers at @rebeccaivers}

Acknowledgements The authors would like to acknowledge the NSW Ministry of Health and the Centre for Health Record Linkage (CHeReL) for access and linkage of data and Dr Mario D'Souza for his statistical support.

Contributors MMD was involved in literature search, figures, study design, data analysis, data interpretation and writing. SBR was involved in literature search, study design, data analysis, data interpretation and writing. KJB was involved in study design, data analysis, data interpretation and writing. DRC and DM were involved in study design, data analysis and writing. RP was involved in study design and writing. RI was involved in study design, data interpretation and writing.

Funding This project was funded by the NSW Agency for Clinical Innovation and the Emergency Care Institute (reference number ACI/D14/2288).

\section{Competing interests None declared.}

Ethics approval The study was approved by the NSW Population Health Services Research Ethics Review Committee.

Provenance and peer review Not commissioned; externally peer reviewed.

Data sharing statement No additional data are available.

Open Access This is an Open Access article distributed in accordance with the Creative Commons Attribution Non Commercial (CC BY-NC 4.0) license, which permits others to distribute, remix, adapt, build upon this work noncommercially, and license their derivative works on different terms, provided the original work is properly cited and the use is non-commercial. See: http:// creativecommons.org/licenses/by-nc/4.0/

\section{REFERENCES}

1. Gonzalez Morganti K, Baufman S, Blanchard J, et al. The evolving role of emergency departments in the United States. Santa Monica, CA: Rand Corporation, 2013.

2. Schuur JD, Venkatesh AK. The growing role of emergency departments in hospital admissions. N Engl J Med 2012;367:391-3.

3. Aboagye-Sarfo P, Mai Q, Sanfilippo FM, et al. Growth in Western Australian emergency department demand during 2007-2013 is due to people with urgent and complex care needs. Emerg Med Australas 2015;27:202-9.

4. Lowthian JA, Curtis AJ, Jolley DJ, et al. Demand at the emergency department front door: 10-year trends in presentations. Med J Aust 2012;196:128-32.

5. Dinh MM, Bein KJ, Latt M, et al. Age before acuity: the drivers of demand for emergency department services in the Greater Sydney Area. Emerg Med J 2015;32:708-11.

6. Hodge A, Hugman A, Varndell W, et al. A review of the quality assurance processes for the Australasian Triage Scale (ATS) and implications for future practice. Australas Emerg Nurs $J$ 2013;16:21-9.

7. Ebrahimi M, Heydari A, Mazlom R, et al. The reliability of the Australasian Triage Scale: a meta-analysis. World J Emerg Med 2015;6:94-9.

8. Carret ML, Fassa AG, Kawachi I. Demand for emergency health service: factors associated with inappropriate use. BMC Health Serv Res 2007;7:131. 
9. Ismail SA, Gibbons DC, Gnani S. Reducing inappropriate accident and emergency department attendances: a systematic review of primary care service interventions. Br J Gen Pract 2013; 63:e813-20.

10. Schull MJ, Kiss A, Szalai JP. The effects of low-complexity patients on emergency department waiting times. Ann Emerg Med 2007:49:257-64.e1.

11. Marriner $\mathrm{C}$. The new problem facing one of the busiest emergency departments in NSW. The Sydney Morning Herald. 18 October 2015. http://www.smh.com.au/action/printArticle?id=1001576448

12. Australian Bureau of Statistics. Estimated Residential Population by single year of age, New South Wales, Australia [Internet]. 2015 (updated 26 March 2015; cited 15 July 2015). http://www.abs.gov. au/AUSSTATS/abs@.nsf/DetailsPage/3101.0Jun\%202014? OpenDocument

13. NSW Health. Guide to the role delineation of health services. 3rd edn. 2002. State Health Publication No. SWS 990186. http://www. health.nsw.gov.au/Hospitals/Pages/role-delineation-levels.aspx Last updated 24 January 2014 (accessed 15 Aug 2015).

14. Australian Institute of Health and Welfare 2013. Australian Hospital Statistics 2012-13: emergency department care. Health services series no. 52. Cat. no. HSE 142. Canberra: AlHW.

15. Atenstaedt R, Evans K. Emergency departments: better safe than sorry? Emerg Nurse 2015;23:20-2.

16. Williams A, O'Rourke $P$, Keogh $S$. Making choices: why parents present to the emergency department for non-urgent care. Arch Dis Child 2009;94:817-20.

17. Mathison DJ, Chamberlain JM, Cowan NM, et al. Primary care spatial density and nonurgent emergency department utilization: a new methodology for evaluating access to care. Acad Pediatr 2013:13:278-85.

18. Nagree Y, Camarda VJ, Fatovich DM, et al. Quantifying the proportion of general practice and low-acuity patients in the emergency department. Med J Aust 2013;198:612-15.

19. Rocovich C, Patel T. Emergency department visits: Why adults choose the emergency room over a primary care physician visit during regular office hours? World J Emerg Med 2012;3:91-7.
20. Cowling TE, Cecil EV, Soljak MA, et al. Access to primary care and visits to emergency departments in England: a cross-sectional, population-based study. PLOS ONE 2013;8:e66699.

21. Dale J, Lang $\mathrm{H}$, Roberts JA, et al. Cost effectiveness of treating primary care patients in accident and emergency: a comparison between general practitioners, senior house officers, and registrars. BMJ 1996;312:1340-4.

22. Khangura JK, Flodgren G, Perera R, et al. Primary care professionals providing non urgent care in hospital emergency departments. Cochrane Database Syst Rev 2012;11:CD002097.

23. Jennings N, Clifford S, Fox AR, et al. The impact of nurse practitioner services on cost, quality of care, satisfaction and waiting times in the emergency department: a systematic review. Int $J$ Nurs Stud 2015;52:421-35.

24. Greenfield G, Ignatowicz A, Gnani S et al. Staff perceptions on patient motives for attending GP-led urgent care centres in London: a qualitative study. BMJ Open 2016;6:e007683.

25. O'Cathain A, Knowles E, Maheswaran R, et al. A system wide approach to explaining variation in potentially avoidable emergency admissions: national ecological study. BMJ Qual Saf 2014;23:47-55.

26. National Home Doctor Service [Internet] 2015 [cited 17 February 2016]. http://www.homedoctor.com.au/

27. Selby JV, Fireman BH, Swain BE. Effect of a copayment on use of the emergency department in a health maintenance organization. N Engl J Med 1996;334:635-41.

28. Jung H, Do YK, Kim Y, et al. The impact of an emergency fee increase on the composition of patients visiting emergency departments. J Prev Med Public Health 2014;47:309-16.

29. Anantharaman V. Impact of health care system interventions on emergency department utilization and overcrowding in Singapore. Int J Emerg Med 2008;1:11-20.

30. FitzGerald G, Toloo GS, Aitken P, et al. Public use and perceptions of emergency departments: a population survey. Emerg Med Australas 2015;27:336-42.

31. Harris P, Whitty JA, Kendall E, et al. The Australian public's preferences for emergency care alternatives and the influence of the presenting context: a discrete choice experiment. BMJ Open 2015;5: e006820. 